\title{
Research and Development of Knowledge-based blanking dies expert system $^{1}$
}

\author{
Baofu Sun ${ }^{1, a^{*} \text {, Zhiwei Zhang }}{ }^{2, b}$ \\ ${ }^{1,2}$ Guilin University of Technology, Guilin Guangxi, China \\ a1204605467@qq.com, ${ }^{b} 516449261 @ q q . c o m$,
}

\begin{abstract}
Keywords: KBS blanking die Database
\end{abstract}
Abstract. With the rapid development of China's manufacturing industry, the market demand is growing mold. Since China's accession to WTO, the rapid development of the mold industry with $15 \%$ annual growth rate. Mold manufacturing enterprises, especially the production cycle mold stamping die have become increasingly short. Therefore, the development of an efficient, professional punching die expert system is particularly necessary. In this paper, the basic structure of the knowledge-based system, the blanking die design knowledge and rules needed to organize, the establishment of a knowledge-based system ( KBS ) architecture, the purpose is to accelerate the development speed of the mold as soon as possible on the market.

\section{Introduction}

In order to meet the fierce market competition, a considerable number of manufacturing equipment manufacturers focused its attention on how to shorten the production cycle of the product up. The topic will focus on how to develop an efficient and reliable expert system that issues research, and according to their function, which is positioned as a design expert system. By studying this topic, we study how the human expert design experience, the actual production experience, all aspects of the production design rules, expert knowledge of the structure to form a systematic structured knowledge base, establish a reasonable knowledge of intelligent reasoning design Wizard system, and finally, the design results will be optimized and interpretation. In order to achieve fast and efficient research and development purposes.

Domestic and foreign expert system based on knowledge of the purpose is to adapt to today's increasingly fierce market competition, the openness of knowledge engineering, so that the current rapid development of expert systems development. In 2001, foreign K. Kawamura and other designs a concrete bridge grading system used to determine the level of the bridge. Its clever use of the relevant principles of fuzzy neural network is a hybrid expert system based on knowledge representation. In 2004, KWChau. Design and development of the expert system fluid holding structure, the expert system to establish the overall framework of a knowledge-based expert system, to achieve some functionality. In 2009, Kun Chen is designed based on knowledge of mold design expert system, the expert system he designed to integrate the design and production of human experience design experts to optimize the inference mechanism to achieve the input parameters required product, material requirements, Reasoner design inference, and drawing programs to determine the output of several steps. In 2014,Jihong Liu development of rotating machinery vibration fault diagnosis expert system. LabVIEW uses a visual language to develop interactive expert system, the system can rotor mass unbalance fault diagnosis, with high practical value.

The design of expert system is divided into the following main modules designed stepwise. Expert System Knowledge Base database design can refer to the general store for information, call management and troubleshooting techniques. Algorithm designer reasoning blanking die in the knowledge of expert system based on $\mathrm{C}++$ can be used in common judgment statement. Product management and process graphics database to form a system of standardized parametric design of a system to facilitate the inference queries and calls. 
Expert system from being presented to the present has gone through three stages of development, is currently the fourth stage of development forward. Future systems will be more expert knowledge, many experts work together to quickly solve engineering problems efficiently, and through artificial neural network of independent "study" advanced intelligent design system.

\section{Blanking die based on knowledge of expert system features}

Expert system is an intelligent design features a computer program with its functions including the analysis of the problem, verify that judgment, logical reasoning of these three areas. Among them, the logic is the core functions of the expert system, how to design a simple and efficient inference engine is the key problem, which directly affects the accuracy of the inference result. In the beginning of the design should take this into account, all of the programming should be carried out around this central point.

Compared to the advantages of a human expert, the expert system is not affected by time, place, fatigue, and other factors, and more stable than human experts to accelerate the flow of knowledge and experience of personnel, expert systems can also set a number of experts in the field design experience, to improve the system, the design and development process to minimize the limiting factor. Another important feature of the expert system is his versatility, because the expert system is separate from the database and inference engine, if the database knowledge extraction, resulting expert system is an empty frame, when the addition of a field when engineering and technical knowledge stored in the knowledge database, when modifying the appropriate inference inference algorithm, the expert system then it becomes able to solve another problem of expert systems. Of course, this system is designed for people who, after all, so his knowledge of the maintenance and expansion of the database also needs to be updated artificially.

Expert system based on knowledge, human experience is the production design experts, formula parameterization, standardization, the use of ACCESS and the establishment of a database to integrate lessons learned accumulated induction, explaining the results of the design. Its main feature is a high flexibility, many constraints obtained from a given blanking die designed to meet the requirements of the results; able to analyze the interaction between the various sub-questions and deal with problems between the child; able to construct a viable experimental design, and get the blanking die design improvements, using existing proper design of the new design to make a reasonable explanation; is a human expert level have the ability to solve practical problems of intelligent software design system [1].

\section{Knowledge-based expert system mainly architecture blanking die}

The research perspective based on knowledge, systematic study of stamping die design methods, blanking process and mold CAD technology. Mainly from the establishment of the knowledge base of the Blanking Die; expert system inference engine production, and increase the data expansion modules can be used for databases, knowledge acquisition and expansion of the knowledge base. So that the inference engine in operation Projects can learn more, higher design efficiency.

First, the establishment of mold design knowledge is to involve the separation of knowledge from a number of sources of knowledge out, after finishing the systematic knowledge of these computer can recognize language compiler. The main source of knowledge of human experts in long-term knowledge and experience related to the structural design, process design knowledge and experience, as well as existing national design specifications, guidelines. In the mold design knowledge base established, we encountered some vague knowledge of experts, such as: vibration strength, minor damage, serious injury, moderate damage, and so on. These fuzzy knowledge there is no uniform standard to measure the degree of strength, there is no standard to measure the severity of the damage is like. If the reasoning is in the design calculations use these data to design a product will cause great uncertainty, there is likely to affect the performance of all aspects of the mold, which requires engineering staff in the program proposed program To make careful review. This is the aspect of 
knowledge acquisition and utilization of knowledge; the other is a key aspect of knowledge, rationality is directly related to the efficiency of knowledge representation knowledge base, which is the core problem of artificial intelligence. Because the system is formed in accordance with the rules to run only dead, it is a production rule-based expert systems. Knowledge representation knowledge to maintain operation characteristic mapping [2].

Second, the process graphics, product management database design, the part most important job is parametric part model. Here it comes to the problem of parametric drawing is the basic structure of parts previously determined set qualification form part of the structure and parameters of the design in the future by modifying the parameters defining conditions and design specifications of different products [3]. Whatever the mold, generally consists of the following components: mold working parts section, guides, etc., so that part of the library to include blanking piece of material, project examples gallery, library typical mold assembly, mold standard parts libraries. Build a parametric model the various parts to form three-dimensional parametric model library.

Third, the establishment of expert system inference mechanisms. In the die design process, from design to mold design process has a significant experience in leading features [4-5]. An important requirement for the expert system reasoning is simple and efficient, it is necessary to have a large number of design knowledge, but also have the ability to apply knowledge to solve practical engineering problems, and the results can be obtained by inference be checked to see if it meets design requirements, if they meet the requirements, then output to the user interface for the selection of design engineers, decision-making; if you do not meet the design requirements, after analysis of the current results will design, integrate new data into the database, again screened by the inference engine Knowledge extract useful knowledge to re-design reasoning, this cycle until a solution consistent with the design criteria, the entire design process was ended [6-7]. Reasoning is making major mimic human engineering and technical personnel of several key steps during product development: design and carry out programs to determine the overall structural design, determine the parameters of each part. Among them, the inference engine inference engine effectively combine these three parts, to speed up the design process of the program.

As shown in Figure 1, the first to establish the parameters of the design knowledge, including knowledge of structural design, process design knowledge, design specifications, to achieve this level of design should have the production capacity levels; secondly to establish mold products can be dynamically updated graphics technology, product management database; and third, the development of mechanisms that can be used to complete the design reasoning; and finally above each module integrated into the UG platform, forming a platform with UG blanking die intelligent design system [8].

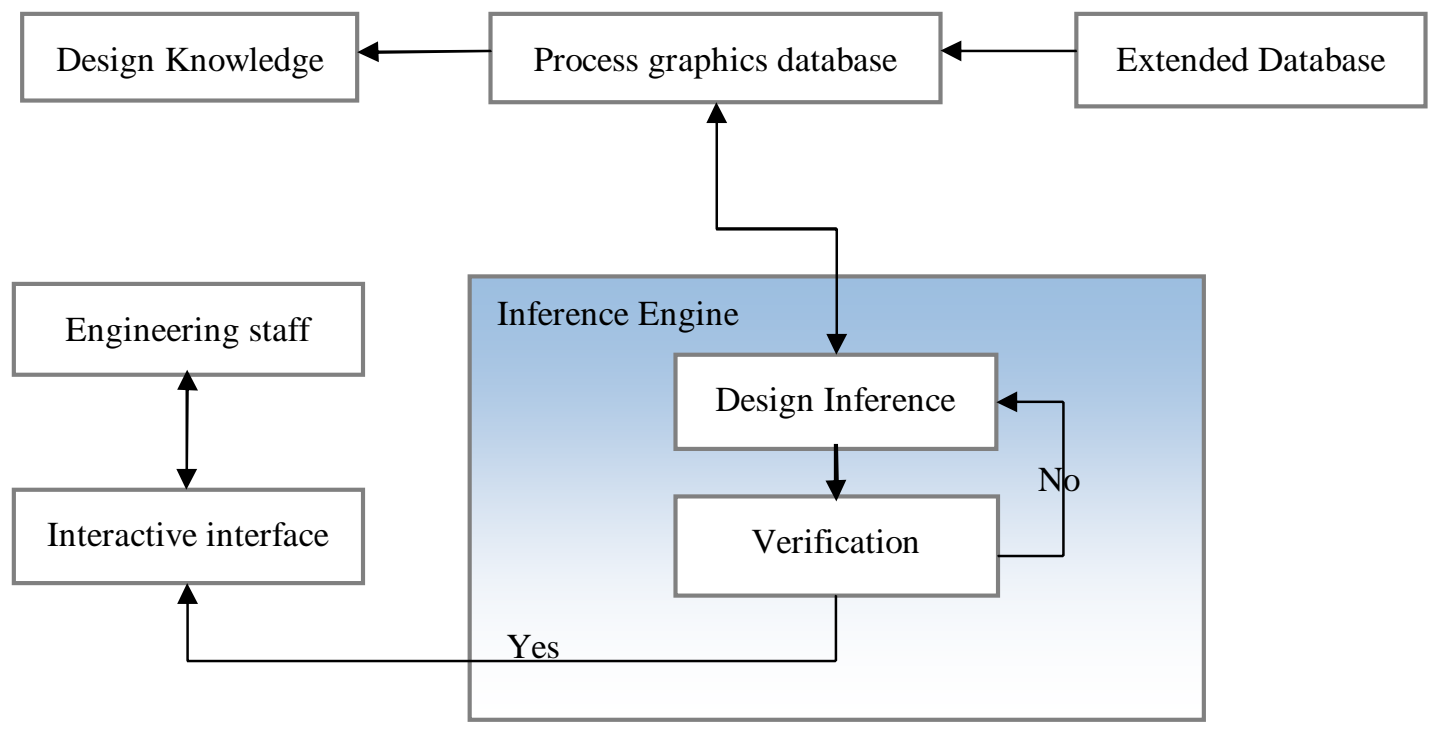

Figure 1 This is based on the blanking die expert knowledge of the overall system architecture diagram 


\section{Blanking die establish expert system program}

We use UG / Open MenuScript to establish a special menu for your program, menu script file extension * .men and save the file in the startup directory [9]. It was briefly summarized according to the type of mold. And depending on the frequency of use of various molds ranking order of the menu bar is optimized to make the software more humane, intelligent.

We use UG / Open UIStyler maker dialog, VC ++ already contains template files available to users with a dialog application UG / Open API program framework [9]. In layout design parts processing parameter input, for example, by calling the UG / Open API functions and file access layout_design_btn.dlg resources, to achieve part input parameters edit dialog. Design of the dialog box in a simple, clear, easy-to-design principles to design. In the establishment of expert systems for the program to pay attention to the modular design, ease of maintenance and future upgrades updates.

\section{The program runs}

Figure 2 shows the work flow of the expert system.Each module is linked compiled program is successful, it can open the software to run and debug. Due to space limitations reasons, each part of the program not going to repeat them. The whole process only a simple program running show. It's working process is such that the three-dimensional digital model designer blanking member input through interactive interface computer, the expert system will automatically analyze the needs of the workpiece machining technology, the standard requirements. Then retrieved from the database call phase approaching design, by inference engine for data integration checking, preliminary design, through the interactive interface is presented to the designer, the designer in view if considered to meet the design requirements, then the end of the design process expert system to complete the task. If designers think design is unreasonable, change the value of the relevant parameters can be set once again let the expert system to design the new program.

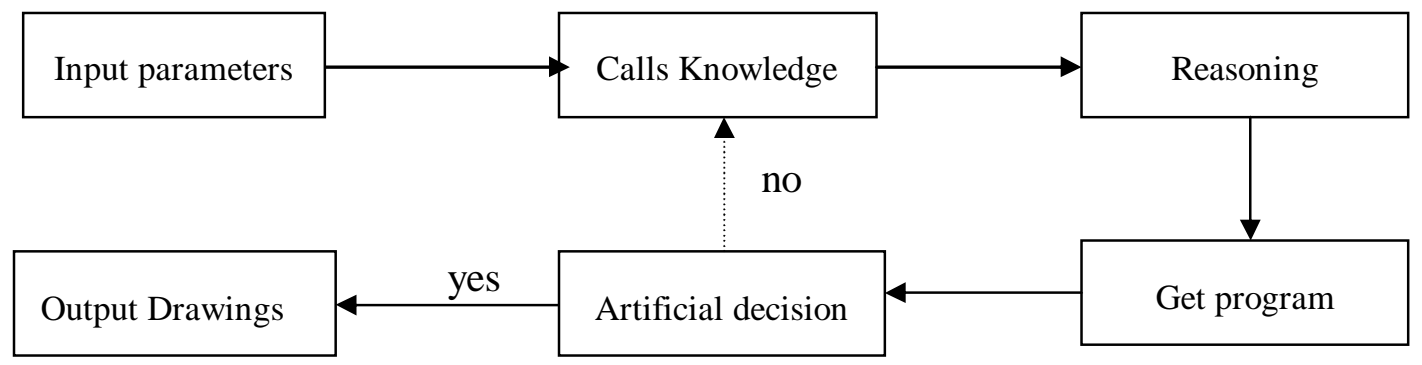

Figure 2 Work process

The design, mold design and construct a preliminary framework for expert systems that can meet most of the mold design. Especially for punching mold design, the expert system has more comprehensive design capabilities. The procedure for use of the system features and details have yet to be professional engineering and technical personnel to find and perfect.

\section{Conclusions}

Mold production generally through the lengthy design process, mold designers rely heavily on experience in the design, production cycle is too long. The development will UG7.5 as a platform, the use Visual C ++ 6.0 in the UG / Open MenuScript and UG / Open UIStyler to develop, produce a more comprehensive feature-aided design system:

(1)The establishment of a more perfect punch Knowledge cut molding, process graphics and product management database, parametric drawing, process calculation program modules. Build a more complete good performance intelligent CAD system. 
(2)The system to accelerate the punching mold design, mold shorten delivery cycles, improve product quality, enhance the overall competitiveness of the product has a more profound significance. It is a more reasonable attempt coming toward the intelligent computer-aided design software design.

(3) This expert system is also good at solving those problems can not be solved with the algorithm can also be used to solve problems that are not standardized and systematic. The system can cope with the actual needs of the practical application of scientific research, product design, production and other aspects of life, with high practicality.

(4)Expert system designed in this article has a relatively good development performance, providing a more complete framework for the development of expert systems in other areas, the use of this framework can replace the knowledge database and reasoning, thereby becoming another expert systems, accelerate product development speed.

\section{Acknowledgment}

The corresponding author of this paper is Baofu Sun and Zhiwei Zhang. This paper is supported by scientific research fund of Guangxi provincial education department, China (Gui Jiao Ke Yan [2010] NO. 14). Authors would like to express their sincere gratitude to all domain experts for providing their expertise in the development of proposed knowledge based system. In this case, the experts in this field grateful for written comments presented herein.

\section{References}

[1]Peiqi Liu,Development and application of a new generation of expert systems technology, Xi'an In China(2014):1-12

[2]Xiaoling Shen,Research and Implementation of a three-dimensional standard mold punching Library Technology,Zhongnan Forestry College(2003)

[3]Suoqing Yu,Liqing Zhang,Gaobing Wan,Liyong Ni.Research and Development Die CAD System,Mechanical design and manufacturing,2010,p.232-233.

[4]Jun Chen,Xiaoxiang Shi,Zhen Zhao,Hongbo Yang,Gang Chen,Xueyu Ruan,KBE key technology and its application in modern intelligent die design,Forging Technology,2003,04:47-50.

[5]. From knowledge based software engineering to knowware based software engineering,Science in China(Series F:Information Sciences),2008,06:638-660.

[6]Jun Zhang,Knowledge-based industrial design of complex products and application support system research,Hunan University,Changsha In China(2013)

[7]Baofu Sun,Research and Development of Knowledge-based injection mold gating system, Mechanical Research \& Application,2008,04:87-89+92.

[8]Siyi Li,UG-based research and development of multi-position progressive die design system,South China University of Technology(2012)

[9]Yong Huang,Bolin Zhang,UG secondary development and database application foundation and a typical example,Beijing In China,2008.1:240-251. 